\title{
Documentation of Discourse-related Particles in North Hail Arabic
}

\author{
Alshamari Murdhy Radad ${ }^{1,2}$ \\ ${ }^{1}$ Hail University, Hail, Saudi Arabia, \\ ${ }^{2}$ College of Arts, English Language Department \\ $\mathrm{PhD}$ student in Linguistics at Newcastle University, School of English Literature, Language and Linguistics, UK, \\ Newcastle Upon Tyne NE17RU \\ Correspondence: Alshamari Murdhy Radad, PhD student in Linguistics at Newcastle University, School of English \\ Literature, Language and Linguistics, UK, Newcastle Upon Tyne NE17RU
}

Received: November 19, 2015

Accepted: December 3, 2015

Online Published: December 7, 2015

doi:10.5430/elr.v4n4p44

URL: http://dx.doi.org/10.5430/elr.v4n4p44

\begin{abstract}
The current research investigates a range of discourse particles used in North Hail Arabic, a variety spoken in Saudi Arabia. It delves into their pragmatic functions related to discourse. Investigating 17 discourse particles, the current research argues that they are associated with specific discourse/pragmatics functions: speaker-positive, speaker-negative, evidentiality, and discourse coherence. Additionally, the current research introduces a general syntactic analysis for these particles, assuming that they are heads, associated with discourse features, have their own functional projections and are base-generated in the left periphery. It shows that these particles are different in terms of whether they are able to be resumed by a pronominal clitic or not. For this, the study attributes this behaviour to whether the given particle has a set of $\Phi$-features (phi-features) or not. All in all, the current research is meant to bring these particles to the fore, suggesting them as a rich area for different linguistic domains (i.e., syntax, semantics, pragmatics, etc.).
\end{abstract}

Keywords: Discourse particles, North Hail Arabic, Resumption, Evidentiality, Coherence

\section{Introduction}

Varieties of Najdi Arabic show different mechanisms by which speaker's attitudes towards the propositional content of utterances can be expressed (cf. Ingham 1994). One example of this difference lies in the way discourse-related meanings are reflected. For instance, North Hail Arabic (NHA), one dialect of Najdi Arabic, utilizes a wide array of discourse particles (C-particles) that reflect speaker's meanings without contributing to the propositional content of the accompanying clause (cf. Hirschberg \& Litman 1993). Such a use is mainly motivated by the issue that C-particles are endowed with a set of discourse interpretive properties which are able enough to deliver speaker's attitudes (Fischer 2006).

C-particles have currently been a fertile source for cross-linguistic research (Schourup 1999). Their semantic scope and interaction with different sentential components have attracted many researchers to work them out, attempting to explore their actual contribution to sentence processing (Fischer 1998, 2000, Stede \& Schmitz 2000, Taboada 2006, Strauss \& Xiang 2009, Taha et al 2014, and Al-Jarrah et al 2015). By the same token, C-particles have been increasingly used as clues for underlying sentence structure and left periphery. Their position and syntactic behaviour with core sentential arguments (i.e., subject and object) have been increasingly utilized as a window for how sentences are structured as far as syntax is concerned (Zimmermann 2004, 2011, Haegeman \& Hill 2013, and Biberauer et al 2014).

On the other hand, although NHA and other Arabic dialects are rich in such particles, few studies explored or even documented them (see, Alshamari 2015a, b). Motivated by the importance of C-particles as well as the lack of studies dealing with them at the level of NHA, the current paper aims at documenting and partially analysing C-particles used in this Arabic variety. It precisely looks at bringing C-particles used in NHA to the fore, exploring their discourse functions. Furthermore, this research provides a syntactic account of the selected particles within the recent generative reasoning.

The main idea advanced is that, given the pragmatic function of the selected C-particles as well as their interaction with the C domain, I propose that they are C-related particles, instantiating their own projections (Cruschina 2009), 
and are syntactically positioned in the speaker-related domain (cf. Sheehan and Biberauer 2011 and Struckmeier 2014), i.e., the left periphery in the sense of Rizzi (1997). In addition, following Aikhenvald (2004), I propose that some NHD discourse particles are first used to express speaker's attitudes towards the propositional content of his/her utterance, and, second are grouped into two categories: evidential particles, speaker's oriented, and coherence particles in the sense of Stede \& Schmitz (2000).

The following discussion is organised as follows. Section 2 sketches out the main works related to discourse particles and the dialect I am addressing here. Section 3 analyses the pragmatic functions of the surveyed particles. Some pragmatic and syntactic discussion is inserted in section 4. Section 5 concludes the research, highlighting its contribution and limitations.

\section{Literature review}

Cross-linguistically, discourse particles in general, (C-particles in this paper), have been central to the linguistic theory due to the fact that they are, interestingly, assumed to be an elusive category. They have developed properties different from other elements- Adv, N, A (Struckmeier, 2014). It is commonplace that such a property has the consequence that discourse particles are an unclear notion in syntax, (Zwicky, 1985), from which their pragmatic functions can be read off. Recently, a huge bulk of research in linguistic theory highlights that C-particles, in fact, interact with the other systems of grammar- pragmatics, semantics and syntax; hence, triggering syntactic analysis to determine their positions (Biberauer et al, 2014). For instance, it has been posited that C-particles fall outside of the sentential boundary of the clause, and so, they do not contribute to the propositional content of the utterance, being mainly related to the speaker-attitude (Hirschberg \& Litman, 1993; Stede \& Schmitz, 2000; Aikhenvald, 2004). Such pragmatic-related properties have motivated many linguist to investigate the positions C-particles occupy in the syntactic structure, adopting modern generative syntactic approaches, mainly Rizzi' (1997) Split CP Hypothesis (Biberauer et al, 2014; Hack, 2014; Struckmeier, 2014). For instance, in the modern generative literature, regarding their positions, it has been proposed that C-particles, having a discourse featural make-up, head articulated projections in the C-domain of the clause; that is, they are encoded in syntax and instantiate their own syntactic projections (Biberauer \& Sheehan, 2011; Cruschina, 2009). By the same token, significant research stresses that $\mathrm{C}$-particles are considered to be diagnostics for the C-domain exhibited by a given language; hence, the interaction between the lexical-functional domain on the one hand and the discourse-domain on the other is best seen when particles are utilized (Roussou, 2000; Zimmermann, 2004). However, it seems fair to say that there is lack of research on C-particles in dialectal Arabic, despite the richness these dialects maintain. Recent works are advanced by (Alshamari, 2015a, b), which tackle a number of discourse particles in one level of grammar- pragmatics.

\section{The particles (Note 1)}

\subsection{Gid}

Sid relates some entity to a state of affairs based on presupposed knowledge of the speaker. Using this particle, the speaker gives coherence to the running dialogue. Hence, following Stede \& Schmitz (2000), this particle is a discourse-coherence particle. Consider the following sentence:
(1) Sid
Firas
nam
Prt
Firas
slept.3SG.M
'As if Firas slept.'

The speaker says this utterance as a response to an action Firas did. The speaker approximates this state of Firas's to something that is available in the speaker's common ground, i.e., something that Firas usually does. The speaker expresses his attitudes towards the proposition of his utterance. Consider the following dialogues for concreteness:

Speaker A: Pl-Payam haði Pldzaw lat'eef ma?ain-uh b-qalb Pas ${ }^{\varsigma} \mathrm{s}^{\complement}$ aif
Days these weather cool although-it in-heart the.summer
'These days the weather is cool although it is the middle of summer.'
Speaker B: La?in-a b-mantiqah dzabaliyah. haða naseem Paldzabal
Because-we in-area mountainous this breeze the-mountain
'That is because we are in a mountainous area. This is the mountainous breeze.'




$\begin{array}{rlll}\text { Speaker A: s`atz } & \text { Gid } & \text { hal-dzaw } & \text { b-ribee } \\ \text { Right } & \text { Prt } & \text { Dem-weather } & \text { in-spring }\end{array}$

'Right! As if it is spring.'

$\begin{array}{rllllllll}\text { Speaker A: Rah } & \text { Paqueeb } & \text { fatrah } & \mathrm{t}^{\mathrm{s}} \text { aweelah } & \mathrm{w} & \text { Pakeed } & \text { rah } & \text { iftaq } & \text { luk } \\ \text { FUT } & \text { leave.I } & \text { period } & \text { long } & \text { and } & \text { surely } & \text { FUT } & \text { miss.I } & \text { to-you }\end{array}$

'I will leave for a long time, and I will surely miss you.'

Speaker B: Xal-na Pala Pitisal
Keep-us on contact
'Let's keep in touch,'

$\begin{array}{rllllcl}\text { Speaker A: Pakeed! } & \text { Pana } & \text { mfaGil } & \text { kil } & \text { fabakat } & \text { atawas }{ }^{\complement} u l & \text { PalPidztimaSiyah } \\ \text { Surely! } & \text { I } & \text { activating } & \text { all } & \text { networks } & \text { communication } & \text { social }\end{array}$

'Surely! I have activated all the social media.'

Speaker B: Bs'arahah! Bwudzu:d hashabakat Gid-uk maS-na

Frankly! With those-communication media Prt-you with-us

'Frankly! With those communications media, it is as if you are with us.'

As shown in dialogue (2), Speaker A expresses his/her feeling towards the status of the weather, being cool, which is not expected given that the utterance time of the clause is in the middle of summer. Having received feedback from his colleague that the cool weather is due to the mountainous breeze, Speaker A, then, approximates the status of the (cool) weather to the most likely resembling entity available in the common ground; that is, spring. The same behaviour is captured in (3), where Speaker B approximates the use of social media (by which she can talk to and see her friend via smart phones with which certain Apps are compatible) with the situation in which her friend is actually present, not away. This so being, Gid is an approximant $\boldsymbol{C}$-particle connecting the propositional content of the adjoining clause to some past discourse the speaker is aware of. This discourse, in turn, must belong to the some entity mentioned in the discourse.

\section{2 zad \& ?adzal}

Zad and Padzal are best classified as negative-attitude particles. They are used when the speaker expresses his/her negative attitudes towards the propositional content of the accompanying utterance. Consider the following dialogue:

(4)

$$
\begin{array}{ccc}
\text { Speaker A: } & \text { rah nafrab } & \text { qahwah } \\
& \text { Fut drink.we coffee } \\
& \text { 'We will drink some coffee.' }
\end{array}
$$

\begin{tabular}{|c|c|c|}
\hline Speaker B: & $\begin{array}{l}\text { Sindhum } \\
\text { have.they.INTRG }\end{array}$ & $\begin{array}{l}\text { qahwah } \\
\text { coffee }\end{array}$ \\
\hline
\end{tabular}

'Do they have coffee with milk?'

Speaker A: La

No

'No.'

\begin{tabular}{|c|c|c|c|}
\hline $\begin{array}{l}\text { Speaker A: taSal } \\
\text { Come.Imprtv }\end{array}$ & $\begin{array}{c}\text { miSi } \\
\text { with-me }\end{array}$ & $\begin{array}{l}\text { Sala } \\
\text { al }\end{array}$ & $\begin{array}{c}\text { Palraqal } \\
\text { teast }\end{array}$ \\
\hline
\end{tabular}

$\begin{array}{llccl}\text { Speaker B: } & \text { Zad/Padzal } & \text { ma } & \text { rah } & \text { Parooћ } \\ & \text { Prt/Prt } & \text { Neg } & \text { FUT } & \text { go.I }\end{array}$

'Then, I'll not go with you.'

'Come with me, at least we can chat.' 


$\begin{array}{lllll}\text { Speaker A: } & \text { t'ayib. } & \mathrm{Zad} / a d_{3} a l & \text { Pat }{ }^{\uparrow} l u b & \text { Ja:e } \\ & \text { Fine } & \text { Prt/Prt } & \text { order.I } & \text { tea }\end{array}$

'Fine (I'll come with you) though I will order tea.'

\subsection{Sumr}

Sumr is homonymous with the lexical word Sumr, with a literal meaning age. When used as a particle, it has an evidential import emphasising the notion that the propositional content of the accompanying utterance is totally true (cf. Alhaisoni et al 2012). When using Sumr, the speaker has concrete, compelling evidence towards the propositional content of his/her utterance of which he/she is certain due to the substantial evidence available. Consider the following sentence:

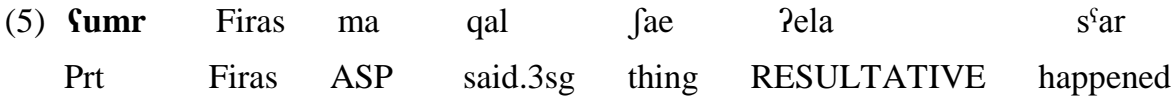

'Whatever Firas has said would happen, it has happened.'

Sentence (5) is understood as follows: it is evident that up to the utterance time, whatever Firas has said would happen, it has indeed happened, without any exceptions. If Sumr is dropped from sentence (5), it follows that the sentence interpretation becomes of less evidentiality, as the occurrence of the phrase denoting

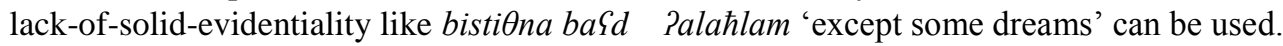

\begin{tabular}{|c|c|c|c|c|c|}
\hline Firas & $\mathrm{ma}$ & halam & & Pela & \\
\hline Firas & ASP & dreamed.3sg & dream & RESULTATIVE & came true \\
\hline (bistiOna & baSd & Palaћlam) & & & \\
\hline (except & some & dreams) & & & \\
\hline
\end{tabular}

'Whatever dream Firas has dreamed has come true (except some dreams).'

What should be noted here is that Sumr co-occurs with the Aspectual particle $m a$ and the resultative particle ?ela. ma and Pela interact with one another to compose the proposition, while Sumr scopes over the whole proposition to render it highly-evidential. The latter assumption is made because the Aspectual ma determines the temporally bounded number of actions Firas has performed up to the utterance time (UT) in the sense of Reichenbach (1980). The resultative particle Pela denotes that these actions were, to some extent, true. Sumr, on the other hand, bearing solid evidentiality, takes wide scope over the whole proposition. Hence, it colours the proposition with Solid-Evidentiality reading. This so being, Sumr can be termed a solid-evidentiality particle. (Note 2)

\subsection{Pisim}

The particle Pisim is homonymous with the lexical word Pisim, with a literal meaning name. Pisim, as a particle, can be seen as an evidential particle. However, it differs from other evidential particles in terms of the amount of evidentiality it expresses. Additionally, observations related to this particle indicate that it has two readings, depending on the proposition it scopes over. First of all, ?isim can be used with a proposition marked with futurity. Consider the following sentence:

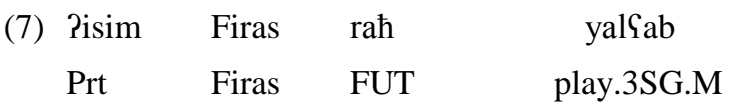

'Firas will most likely play.'

In (7), the clause expresses futurity, and due to Pisim, the speaker emphasises the notion that the propositional content of his/her utterance is totally true, but this emphasis is, though, not dependent on concrete evidence, but rather on the available strong indications which can suffice to affirm the truth value of the proposition. Now compare (7) with (8) below:
(8) Pisim
Firas laSab
Prt Firas played.3SG.M
'Firas has already played.'

When Pisim is utilized with a proposition marked with perfectivity (past-tense), on the other hand, the speaker emphasises the notion that the propositional content of his/her utterance is totally true, depending on concrete evidence. In fact, this variation shouldn't be surprising since events/actions/states expressed by clauses marked with 
perfectivity bear strong evidentiality, which, by theory, entail telicity of such actions etc. (cf. Alhaisoni et al 2012). For concreteness, consider the following dialogue:

(9)

$\begin{array}{cccccc}\text { Firas: marhaba! } & \text { rah } & \text { Paৎti:-k } & \text { kitab } & \text { Gun } & \text { alnahu } \\ \text { Hi! } & \text { FUT } & \text { give-you } & \text { book } & \text { about } & \text { syntax }\end{array}$

'Hi! I will give you a book about syntax.'

$\begin{array}{cccccc}\text { Dilara: Jukran! } & \text { mumkin } & \text { Paxð-h } & \text { baћd } & \text { Piz'uhur } & \text { Sala Pal-muћaz'arah } \\ \text { Thanks! } & \text { May } & \text { take.I-it } & \text { after } & \text { the.noon in } & \text { the-lecture }\end{array}$

'Thanks! May I take it afternoon, at the time of the lecture?'

Firas: Palhi:n afz'al. ?axaf ?ansa Paw ma Padzi

Now better. Afraid forget.I or Neg come.I

'It is better to give it to you now. I may forget to do so, or may not come at all.'

Firas: aw Pansa Pąti:k-i-yah

Or forget give-you-it

'Or I might forget to give it to you.'

\begin{tabular}{|c|c|c|c|c|c|c|c|c|c|}
\hline $\begin{array}{r}\text { Dilara: bus } \\
\text { But }\end{array}$ & $\begin{array}{l}\mathrm{ma} \\
\mathrm{Neg}\end{array}$ & $\begin{array}{r}\text { Paqdar } \\
\text { can.I }\end{array}$ & $\begin{array}{l}\text { Pafi:1-uh } \\
\text { carry.I-it }\end{array}$ & $\begin{array}{l}\text { Pal-hi:n. } \\
\text { now. }\end{array}$ & $\begin{array}{l}\mathrm{ma} \\
\mathrm{Neg}\end{array}$ & $\begin{array}{l}\text { miS-i } \\
\text { with-I }\end{array}$ & $\begin{array}{c}\text { Jant'ah } \\
\text { bag }\end{array}$ & $\begin{array}{l}\mathrm{w} \\
\text { and }\end{array}$ & $\begin{array}{l}\text { Pismi } \\
\text { Prt }\end{array}$ \\
\hline & $\begin{array}{l}\text {-uk } \\
\text {-you }\end{array}$ & $\begin{array}{l}\text { bi-l-m } \\
\text { in-lect }\end{array}$ & $\mathrm{az}^{\complement} \operatorname{arah}$ & & & & & & \\
\hline
\end{tabular}

'But I cannot carry the book now. I don't have a bag and I will already meet you in the lecture.'

$\begin{array}{lllll}\text { Firas: } & \text { la. } & \text { Pism-i } & \text { qabalt-ik. Palhi:n } & a z^{\complement} \operatorname{man} \\ & \text { No! } & \text { Prt-I } & \text { met.I-you. Now better }\end{array}$

'I have already met you. It is better now.'

'I am already meeting you. It is better now.'

As clear in (9), Dilara uses Pisim to make it evident that she will take the book from Firas later at the lecture time, based on the strong indications she has available (i.e., she will attend the afternoon lecture which Firas would also attend). However, these indications don't suffice to assure that she would get the book, the reason which motivated Firas to use Pisim with the perfective event (that he was already meeting her). This so being, this particle is an evidential particle.

$3.5 s^{\text {said }}$

The particle $\mathrm{s}^{\mathrm{\varsigma}}$ aid is homonymous with the lexical word $\mathrm{s}^{\mathrm{q}}$ aid, meaning hunting. $\mathrm{s}^{\mathrm{f}}$ aid is used to connect utterances with their past discourse in a discourse smooth way. Consider the effect of this particle on the translation of the following clause:
(10) S Said $^{\text {S }}$
Firas nam
Prt Firas slept.3SG.M
'(It should be the fact that) Firas slept.'

$S^{\varsigma}$ aid is used to smoothen the proposition. Based on a state of Firas that the speaker just came to know, the speaker uses $\mathrm{S}^{\complement}$ aid as a discourse-smooth particle to label the proposition as more suggestive than a matter of fact (cf. Stede $\&$ Schmitz 2000). Consider now the following dialogue.

\begin{tabular}{|c|c|c|c|c|c|c|}
\hline (11) Speaker A: & $\begin{array}{l}\text { Firas } \\
\text { Firas }\end{array}$ & $\begin{array}{l}\text { qaSad } \\
\text { woke.up.I }\end{array}$ & $\begin{array}{l}\text { mit?axir } \\
\text { late.he }\end{array}$ & $\begin{array}{c}\mathrm{w} \\
\text { and }\end{array}$ & $\begin{array}{l}\text { fawat } \\
\text { missed }\end{array}$ & $\begin{array}{l}\text { Pal-ixtibar } \\
\text { the-lecture }\end{array}$ \\
\hline
\end{tabular}

'Firas woke up late, and he missed the test today.' 


$$
\begin{aligned}
& \text { Speaker B: } \text { S }^{\text {faid-uh }} \text { kan saharan kil Palbarih } \\
& \text { Prt-he Be.Past staying.up whole lastnight } \\
& \text { 'It should be the fact that he stayed up all last night.' }
\end{aligned}
$$

With (11) in place, it is quite clear that Speaker B attributes Firas's act of waking up late and missing the exam to the assumption that it is likely that Firas stayed up all night; hence, suggestive. In this case, Speaker B allocates Firas some excuses for missing the exam, namely, that Firas stayed up the night for reasons such as studying. Indeed, this is what we mean by discourse-smoothing device.

\section{6 kumma}

Kumma is used to express a negative attitude; where the speaker, relying on the available concrete evidence, expresses his negative attitude towards the proposition. When using kumma, the ultimate results come contradictory although the evidence available for the speaker is dependable. The speaker appears not to be satisfied and is expecting to receive positive feedback etc. Following this line of thought, kumma is best categorised as a negative-attitudinal particle. Consider the following dialogue:

$\begin{array}{rrllllr}\text { Speaker A1: Firas } & \text { qaSad } & \text { mitPaxir } & \text { w } & \text { taPaxar } & \text { Pala } & \text { Pal-ixtibar } \\ \text { Firas } & \text { woke.up.I } & \text { late.he } & \text { and } & \text { late } & \text { on } & \text { the-exam }\end{array}$

'Firas woke up late, and he was late to the exam.'

$$
\begin{aligned}
& \text { Speaker B: kumma Firas fawat Pal-ixtibar } \\
& \text { "It should be the fact that he missed the exam (hopefully not? Or...!)).' } \\
& \text { Speaker A2: ?afwa ixtibar } \\
& \text { Prt test } \\
& \text { Speaker A3: i:h li-lasaf } \\
& \text { Yes for-sorrow } \\
& \text { 'Unfortunately, yes.' }
\end{aligned}
$$$$
\text { Prt-he Firas missed the-exam }
$$

Speaker B is informed by Speaker A that Firas woke up late. Speaker B, as a result, expects adverse consequences of this fact, expressing his negative attitude towards his proposition, namely, that Firas might have missed the exam. However, Speaker B still hopes to elicit a positive response from Speaker A. Such an elicitation is made clear by retrieving good news (as Speaker A2's response using the positive attitude particle ?a/wa), or, otherwise, as in Speaker A3's response, the bad news is confirmed.

\section{7 dzeli}

dzeli, like kumma, is not derived from any other lexical item in NHA. This particle can be seen as a discourse-interrogative particle not only for information such as yes/no constructions, but also for some pragmatic functions it bears. Consider the following clause:

$$
\begin{aligned}
& \text { Speaker A: Firas ma qaSad lilheen } \\
& \text { Firas Neg woke up till now } \\
& \text { 'Firas hasn't woke up.' } \\
& \begin{array}{clll}
\text { Speaker B: dzeli } & \text { Firas } & \text { nam } & \text { (Pasasan) } \\
\text { Prt } & \text { Firas } & \text { slept.3SG.M } & \text { (basically) }
\end{array}
\end{aligned}
$$

'Did Firas sleep? (I thought he didn't)'

The speaker uttering (13) has a previous knowledge that Firas didn't sleep. However, he/she is not informed that the opposite is true, a piece of knowledge accompanied with mirativity in the sense of Aikhenval (2004). As a result, using dzeli (being clause-initial; scoping over the proposition being asked about), the speaker just expresses his/her 
state of affairs being surprised by the fact that he/she had maintained incorrect information. This assumption can be backed up by the assumption that the adverb asasan 'basically' can occur with dzeli.

\section{8 tsan}

tsan is used in cases where an unpleasant event is supposed to occur. This use must be paired with some grounds of given strong indications, when the speaker expresses his/her negative attitudes. Consider the following dialogue:

$\begin{array}{rlllllll}\text { Speaker A: nisi:t } & \text { Padafayah } & \text { Jaвalah } & \text { w } & \text { fi:h } & \text { Gilbat } & \text { Git'ir } & \text { bdzanb-ah } \\ \text { forgot.I } & \text { the-heater } & \text { on } & \text { and } & \text { EXISTENSIAL } & \text { bottle } & \text { perfume } & \text { next.to-it }\end{array}$

'I left the heater on and there is a bottle of perfume next to it.'

\begin{tabular}{|c|c|c|c|c|c|c|c|}
\hline Speaker B: & $\begin{array}{l}\text { tsan } \\
\text { Prt }\end{array}$ & $\begin{array}{l}\text { Padafayah } \\
\text { the-heater }\end{array}$ & $\begin{array}{l}\text { Piltamsat } \\
\text { strike.it }\end{array}$ & $\begin{array}{l}\mathrm{w} \\
\text { and }\end{array}$ & $\begin{array}{l}\text { hrigat } \\
\text { burn }\end{array}$ & $\begin{array}{l}\text { Pal-bait } \\
\text { the-house }\end{array}$ & \\
\hline
\end{tabular}

'(I am afraid that it will be the case in which) the heater will strike and burn the house.'

In (14), Speaker B uses tsan, expecting negative consequences of leaving the heater on while something flammable is left next to it. This can be further clear by the incompatibility of phrases denoting positivity like rah tku:n tamam 'it will be alright' with tsan. Accordingly, this particle is a negative attitudinal particle.

\section{9 jamaar (Note 3)}

jamaar is a speaker-oriented particle, a resultative-marker used to signal the speaker's attitude against the event at hand, when the speaker voices his/her concern about the result of one situation. jamaar is used to introduce a result, one that of an event ending up in an unpredicted, unexpected way, thus, giving a strange result (i.e., anomaly). For instance, consider the following dialogue:

(15)
A: rabat $^{\mathrm{s}}$ halq
Palhs $s^{\mathrm{a}} \mathrm{w}$
rah Paxð-uh
li l-baet ${ }^{\varsigma}$ ari
tied.I mouth
the-horse and
FUT take-him
to the-veterinarian

'I tied the horse's mouth closed and will take him to the veterinarian.'
B: $\int s^{\text {`ar }}$
int thib-uh
w
dayem trakl-uh
bnafsak
What happened you
love.you-him and
always
feed.you-him
yourself

'What happened? You love him and always feed him yourself.'
A: Paxir
marrah madeat 1-uh
1-?akil
b-yidi
Last time passed to-him
the-food
with-my hand
jamaar yabi
yGid`-ni
'Last time I passed him the food with my hand. He wanted to bite me.'

$\begin{array}{llllll}\text { B: } & \text { ваri:b! } & \text { ma } & \text { kan } & \text { yubi } & \text { Pal-Pakil } \\ & \text { Strange! } & \text { Neg } & \text { be.PAST } & \text { want } & \text { the-food }\end{array}$

'Strange! Didn't he (intend to) want the food?'
A: lil?asaf
la
kan yћawil
yৎid
bus
Unfortunately Neg
be.PAST try
bite only

'Unfortunately no; he was trying to bite only.'

In (15), Speaker (A) uses jamaar when mentioning the strange event where he/she attempted to feed his horse, an action he/she normally performs. As clear in the above dialogue, it emerges that the speaker gets perplexed of the reaction of the horse. Instead of accepting the food the speaker tried to give, the horse attempted to bite the speaker's hand. This result of feeding the horse is counted as an apparent anomaly from the speaker's perspective. Speaker (A) told Speaker (B) about this confusing reaction of the horse, introducing the perplexed or confusing result with jamaar. Accordingly, jamaar is used between two discourse segments of which the first one in sequence is the event, and the second one is the result which must be negative (i.e., bad) and surprising at the same time. 


\subsection{0 maar(Note)}

The discourse-based particle maar is used as a concessive marker connecting two contradictory assumptions. In this use, the speaker is highly sceptical of the sentence containing maar. Consider the following dialogue:

(16)

$$
\begin{aligned}
& \text { A: Pal-dzulus Pat'aweel qatil Pak0ar min Patadxeen } \\
& \text { The-siiting the-prolonged fatal more than the-smoking }
\end{aligned}
$$

\begin{tabular}{|c|c|c|c|}
\hline A: haði & ћaqa?iq & w & natayidz \\
\hline & facts & and & results \\
\hline
\end{tabular}

'This is not logical. At least prolonged sitting doesn't destroy the body internally.'

'These are facts and research findings.'

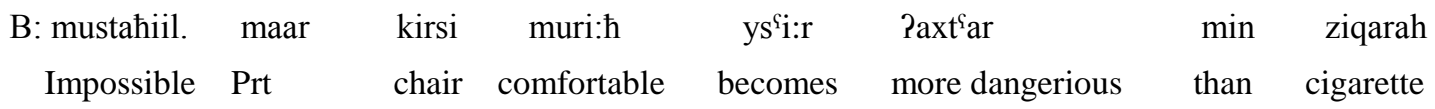

'Impossible! A comfortable chair becomes more dangerous than a cigarette!'

A plausible reading of Speaker's (B's) last utterance, containing maar, is that 'although the chair is comfortable, it becomes more risky than smoking!' It should be stressed that this sentence should be accompanied with an ironical tone which signals that the speaker is highly derisive and sceptical of the utterance. This assumption is also corroborated by the use of distinctive adverbs including mustahiil 'impossible'. This being so, it can be suggested that since maar signals the logically-derived results, it follows that maar can be counted as a pejorative concessive marker.

\subsection{PaOari}

This particle is used when discovering the reason behind an action/fact etc., where such reasons were not expected by the speaker. Consider the following sentence.

$$
\begin{array}{ccc}
\text { (17) PaOari } & \text { Firas } & \text { nam } \\
\text { Prt } & \text { Firas } & \text { slept.3SG.M }
\end{array}
$$

\begin{tabular}{|c|c|c|c|c|c|c|}
\hline A: Firas & yintiz ${ }^{\mathrm{f}}$ ir & bilmal؟ab. & $\begin{array}{l}\text { rah } \\
\text { Went }\end{array}$ & $\begin{array}{l}\text { Palwaqt } \\
\text { the-time }\end{array}$ & $\begin{array}{c}\mathrm{W} \\
\text { and }\end{array}$ & $\begin{array}{l}\text { mahad } \\
\text { no one }\end{array}$ \\
\hline
\end{tabular}

'(It was revealed that) Firas slept.'

As the translation in (17) indicates, ?aAari is a strong evidential particle used by the speaker to identify the real factor/reason/rationale behind an action etc. Consider the following dialogue:

'Firas was waiting in the playing field (to play a football game). Time was going by, and nobody appeared.'

B: wean PilaSebeen? ridzaS?

Where the-players returned.3SG.M

'Where were the players? Did he return back home, then?'

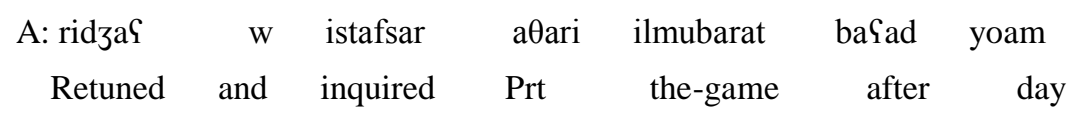

'He returned and inquired, though, the game was scheduled to be played the following day.' 


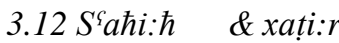

These particles share one pragmatic function, that is, discourse-coherence; triggered by the pragmatic presupposition based on the speaker's knowledge and attitudes towards a particular point mentioned in the flow of the discourse. Consider the following dialogue:

(19)

\begin{tabular}{|c|c|c|c|c|c|c|}
\hline \multirow[t]{2}{*}{ Speaker A: } & Barcelona & Sindhum & mubarat & niha?iyah & assbu: $\mathrm{C}$ & Pildzae \\
\hline & Barcelona & have.they & game & final & week & nex \\
\hline
\end{tabular}

Speaker B: i:h qwiyah

Yes tough

'Yes, it will be a tough game.'

Speaker A: ma-ni mit?akid min PaltaJkeelah yaleet tku:n qawiyah

Neg-I sure from the-squad hope $\mathrm{Be}$ tough

'I am not sure about the squad. I hope it will be tough.'

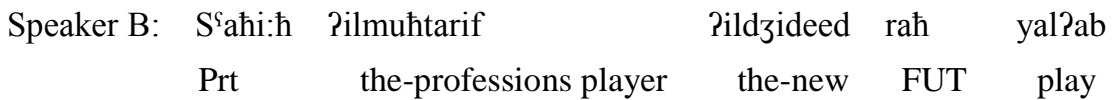

'(The good news by the way is that) the new professional player will play this game.'

Speaker C: xați:r yinhazmu:n

Prt deafeated.them

'(Though, it is likely that) they will be defeated.'

Speaker A: lee

Why

'Why?'

Speaker C: Paslab

Palafibeen Palfananeen

ma rah y jarku:n

Majority the-players the-professional Neg FUT play

'The majority of the best professiona players will not play.'

It can be clearly seen in (19) that $\mathrm{S}^{\varsigma} a \hbar i: \hbar$ and xaț:r are discourse-coherence particles used to introduce information related to the ongoing discourse depending on the presupposed knowledge of the speaker. However, a slight difference holds between them. $\mathrm{S}^{\complement} a \hbar i: \hbar$ is used to suggest positive attitudes, xați:r for negative attitudes.

3.13 tsaif

tsaif is best categorised as an negative-attitude-inquisitive particle, used when the speaker to inquire for more information about something unpleasant he has come to know. Consider the following dialogue:

(20)

$\begin{array}{rllll}\text { Speaker A: Firas } & \text { nisa } & \text { Paldzihaz } & \text { bil-hadi:qah } & \text { Palbarih } \\ \text { Firas } & \text { forgot } & \text { the-laptop } & \text { in-the-garden } & \text { last night } \\ \text { w } & \text { ma } & \text { liq-ah } & \text { Palyoum } & \\ \text { and } & \text { Neg } & \text { found-it } & \text { today } & \end{array}$

'Firas forgot the laptop in the garden last night, and he didn't find it today.'

Speaker B: tsaif (wif sawa?)

Prt (what did.he)

'Oh! What consequences will that have! (What did he do?)' 


$\begin{array}{cccccc}\text { Speaker A: w } & \text { kan.at } & \text { wislat } & \text { Palðakirah majbu:kah b-uh } \\ \text { and } & \text { was.it } & \text { the.USB memory } & \text { connected in-it }\end{array}$

'And the memory card was connected to the laptop.'

In (20), Speaker B shows his/her sorrow for what Firas did, forgetting his laptop in the garden. Optionality of the bracketed phrase suggests that using tsaif alone suffices to make Speaker B provide more information on the negative consequences that Firas would encounter. As a result, Speaker A informs Speaker B that, much worse, the memory card was connected with laptop when stolen.

\subsection{Sankin}

Sankin is used as a discourse-positive- attitude particle, when assigning someone compliments as a result of being amazing. To appreciate this point consider the following discourse:

(21)

\begin{tabular}{|c|c|c|c|c|c|c|c|}
\hline Speaker A: Firas & tаваrab & $\min$ & kan & $\mathrm{s}^{\mathrm{S}}$ евеer & rah & li-dyar & 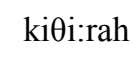 \\
\hline Firas & away & since & was & young & went & to-countries & many \\
\hline $\mathrm{W}$ & $\mathrm{Sa}$ & $\theta$ aqafat & & alfah & & & \\
\hline and & lived & cultures & $\mathrm{Va}$ & & & & \\
\hline
\end{tabular}

'Firas has been away since he was young. He has been to many countries and experienced various cultures.'

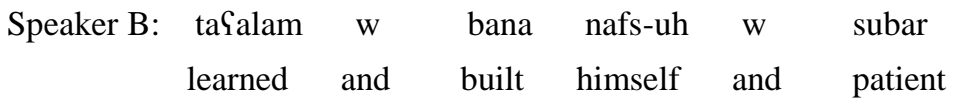

'He learned, was patient and self-made.'

Speaker A: Sankin Firas bat'al

Prt Firas hero

'(I should admit that) Firas is a hero.'

This particle is used only when the speaker shows his positive stand towards the propositional content of his/her utterance.

\subsection{5 fin}

This particle is used when the speaker has convincing pieces of evidence that he would succeed in achieving something, winning a game, for instance. Moreover, fin colours the proposition it scopes over with the sense of challenging due to the confidence the speaker obtains. What might bear this out is that in other varieties (such as Jordanian Arabic and Hijazi Arabic), lexical means are used instead of the particle fin such as (Patahada Firas .....) literally meaning (I challenge Firas...). Consider the following dialogue:

\begin{tabular}{|c|c|c|c|c|c|c|c|}
\hline Speaker A: b-kil & liSbah & $\operatorname{maS}$ & Firas & Pinhazim & korah & $\mathrm{w}$ & sibaq \\
\hline In-all & game & with & Firas & defeated.I & football & and & race \\
\hline
\end{tabular}

$$
\begin{aligned}
& \text { Speaker B: J-baqi liSbah } \\
& \text { Q-remain game? } \\
& \text { 'What is the next game?' }
\end{aligned}
$$

\begin{tabular}{|c|c|c|c|c|}
\hline Speaker B: & $\begin{array}{l}\text { Firas } \\
\text { Firas }\end{array}$ & $\begin{array}{l}\text { qis i:r } \\
\text { short }\end{array}$ & $\begin{array}{l}\mathrm{w} \\
\text { and }\end{array}$ & $\begin{array}{l}\text { int } \\
\text { you }\end{array}$ \\
\hline
\end{tabular}

Speaker A: Palqafz

'Jumping.'

'You are tall but Firas is short.' 


$$
\begin{gathered}
\text { Speaker A: fin Firas yufuz hal-marah } \\
\text { Prt Firas win this-time } \\
\text { 'I challenge Firas this time.' }
\end{gathered}
$$

This particle can be seen as an attitudinal surprizing particle.

\section{Discussion}

\subsection{Pragmatics}

As clearly seen from section 3, NHA has a wide variety of C-particles denoting different but related discourse functions. All of these particles pertain to the speaker's attitude towards the accompanying utterance. They do not contribute (directly) to the propositional content of the utterance but rather reflect speaker's point of views, opinion and attitudes towards the event involved (cf. Ippolito 2007, Fraser 2009, and Fox Tree 2010, among many others).

\begin{tabular}{|c|c|c|}
\hline & C-particle & Functions \\
\hline (1) & Sid & Approximant \\
\hline (2) & $\mathrm{Zad}$ & Negative-attitude \\
\hline (3) & Padzal & Negative-attitude \\
\hline (4) & Gumr & Solid-evidentiality \\
\hline (5) & Pisim & Strong evidential \\
\hline (6) & $s^{\varsigma}$ aid & Discourse-Smooth \\
\hline (7) & kumma & Negative-attitudinal particle \\
\hline (8) & $d z e l i$ & Discourse-interrogative \\
\hline (9) & tsan & Negative attitudinal \\
\hline (10) & jamaar & Resultative-marker \\
\hline (11) & maar & Concessive marker \\
\hline (12) & PaAari & Strong evidential \\
\hline (13) & $s^{\complement} a \hbar i: \hbar$ & Discourse-Coherence \\
\hline (14) & xați:r & Discourse-Coherence \\
\hline$(15)$ & tsaif & Negative-Attitude-Inquisitive \\
\hline (16) & Sankin & Discourse-Positive- Attitude \\
\hline (17) & fin & Attitudinal Surprizing \\
\hline
\end{tabular}
Table (1) below shows the C-particles used in NHA and their concomitant discourse functions:

Table 1. C-particles in NHA and their pragmatic functions

Based on Table 1, it can be assumed that these particles vary in terms of their roles. No one of them has the same function, as compared to others. Nonetheless, it can be neatly drawn that there are four types of C-particles in NHA, as far as the surveyed particles are concerned: speaker-positive, speaker-negative, evidentiality, and discourse coherence. Consider the following table (which is an approximate division, not intended to be perfect): 
Table 2. Typology of C-particles function in NHA

\begin{tabular}{|c|c|c|c|}
\hline speaker-positive & speaker-negative & evidentiality & discourse coherence \\
\hline Sankin & kumma & Sumr & Sid \\
\hline \multirow[t]{6}{*}{ fin } & dzeli & Pisim & Said \\
\hline & tsan & PaAari & jamaar \\
\hline & mar & & $s^{\complement} a \hbar i: \hbar$ \\
\hline & tsaif & & xați:r \\
\hline & $z a d$ & & \\
\hline & ?adzal & & \\
\hline
\end{tabular}

Indeed, table 2 is of key importance because it gives us some underlying clues why such particles are not addressed within any linguistic approach. They are discourse-bound rather than discourse-free. Studies in Arabic linguistics in general and Najdi Arabic in particular have focused on sentences where discourse is neutralized, hence no mention to the particles can be made or even noticed. I leave open the exact discourse-related function of such particles for further research.

\subsection{Syntax}

As related to the syntactic behaviour of C-particles surveyed throughout this research, it appears that they need a huge work to conduct. Their position, scopal properties, their morpho-syntactic properties along with their relation with other elements of the clause, etc. are important and rich topics for scrutiny and investigation regardless of the syntactic theory used. What can be generalized on these particles is that they are discourse particles heading dedicated projections in the left periphery of NHA clause. This generalization is grounded with the fact that the left-periphery is the domain where discourse is intertwined with semantics and syntax. Due to their discourse-related functions, it is more or less clear that C-particles start out life in the left periphery. The assumption that these particles are heads gushes from their behaviour vis-a-vis the subject and object as well as resumption. Some particles can be resumed by a clitic having the same $\Phi$-fractures of the subject (and even the object under some cases). Consider table 3 (Optional O; prohibited P):

Table 3. resumption and C-particles

\begin{tabular}{|c|c|}
\hline Resumption $\mathrm{O}$ & Resumption $\mathrm{P}$ \\
\hline Sankin & kumma \\
\hline fin & maar \\
\hline dzeli & tsaif \\
\hline tsan & $z a d$ \\
\hline Gumr & Padzal \\
\hline Pisim & jamaar \\
\hline PaAari & $s^{\zeta} a \hbar i: \hbar$ \\
\hline Sid & xați:r \\
\hline$s^{\varsigma}$ aid & \\
\hline
\end{tabular}

The general account is that these particles have a set of $\Phi$-features which are uninterpretable in the sense of Chomsky (1995 and subsequent work). The clitic, thus, is seen as a by-product of the valuation process established between the given C-particle and the subject or the object. Compare the following sentence with (1) above.
(23) Sid-uh
Firas nam
Prt-him Firas slept.3SG.M
'As if Firas slept.'

However, the precise nature of this valuation is left open for further research. When the particles do not bear any resumptive clitic, it can be assumed that these particles are defective in the sense that they lack $\Phi$-features. Compare the following sentence with (12B) above 


\begin{tabular}{|c|c|}
\hline (24)*Kumma-uh & Firas nam \\
\hline Prt-him & slept.3SG.M \\
\hline
\end{tabular}

However, again, the exact nature of this valuation and syntactic behaviour of particles is left open for further research.

\section{Conclusion and limitations of the work}

\subsection{Conclusion}

This research is significant not only because it introduces a discourse-related account of the surveyed C-particles in NHA, but also because it highlights them for future research. The main aim was to bring these particles to the fore. It is rather clear that C-particles in NHA have several functions either at the level of discourse building and/or perception. It follows that a study like this cannot be under no circumstances enough to shed light on their behaviour. It was meant to drag researchers' attention to a fecund ground of research and investigation. Hence, any future research can target their pragmatics functions since we are armed with natural tools to underpin how discourse is structured. Furthermore, other line of research can work out their syntactic behaviour which seems far from clear, a matter that imposes itself strongly in the face of interested scholarship. As evident from its title, the current research is grossly speaking a humble attempt to document an area less investigated though rich and worth exploring. My last word is that analysing sentences away from their discourse is like planting without seeds.

\subsection{Added value of the current work and contribution to the field}

1- Documenting particles that have never been explored.

2- Advocating that C-particles are not arbitrary elements in the language but are built to deliver specific functions, semantics or pragmatics, where other language systems balk.

3- This work is another price of evidence that sentences must be paired with the discourse; separating the sentence from its discourse yields no benefit and even endanger difficulty in understanding sentence processing and interpretation.

\subsection{Limitations of the work}

1- Though viewed as comprehensive, this work skips over some other C-particles used in Hail Region, Saudi Arabic, either for less frequency or limitedness to certain regions.

2- A fuller pragmatico-syntactic and discourse account of the surveyed C-particles lies beyond the bounds of the current work for its highly-rooted interference with other modules of grammar; hence room for further research.

\section{References}

Aikhenvald, A. Y. (2004). Evidentiality. Oxford University Press.

Alhaisoni, E., Jarrah, M. A., \& Shehadeh, M. S. (2012). An investigation of evidentiality in the Arabic language. International Journal of Linguistics, 4, 260-273. http://dx.doi.org/10.5296/ijl.v4i2.1600

Al-Jarrah, R. S., Abu Dalu, A. M., \& Jarrah, M. (2015). A Relevance-Theoretical Account of Three Arabic Pragmatic Operators of Concession in a Political Discourse. Lodz Papers in Pragmatics, 11, 51-76.

Alqassas, A. (2015). Negation, tense and NPIs in Jordanian Arabic. Lingua, 156, 101-128.

Alsarayreh, A. (2012). The licensing of negative sensitive items in Jordanian Arabic (Doctoral dissertation, University of Kansas).

Alshamari, M. R. (2015a). Pragmatic Analysis of the Particle вadı in Najdi Arabic. International Journal of Linguistics, 7, 81-93. http://dx.doi.org/10.5296/ijl.v7i2.7176

Alshamari, M. R. (2015b). 1 A Relevance-Theoretical Account of Three Discourse Markers in North Hail Arabic. Studies in Literature and Language, 11, 6-15.

Biberauer, T., \& Sheehan, M. (2011). Introduction: particles through a modern syntactic lens. The Linguistic Review, $28,387-410$.

Biberauer, T., Haegeman, L., \& Kemenade, A. (2014). Putting our heads together: towards a syntax of particles. Studia Linguistica, 68, 1-15.

Chomsky, N. (1995). The minimalist program. Cambridge, Mass: MIT Press. 
Cruschina, S. (2009). The syntactic role of discourse-related features. Cambridge Occasional Papers in Linguistics, 5, 15-30.

Fischer, K. (1998). Validating semantic analyses of discourse particles. Journal of Pragmatics, 29, 111-127.

Fischer, K. (2000). Discourse particles, turn-taking, and the semantics-pragmatics interface. Revue de Sémantique et Pragmatique, 8, 111-137.

Fischer, K. (Ed.). (2006). Approaches to discourse particles, 1-20. Amsterdam: Elsevier.

Fox Tree, J. E. (2010). Discourse markers across speakers and settings. Language and Linguistics Compass, 4, 269-281.

Fraser, B. (2009). An account of discourse markers. International review of pragmatics, 1, 293-320.

Hack, F. M. (2014). The Particle Po in the Varieties of Dolomitic Ladin-Grammaticalisation from a Temporal Adverb into an Interrogative Marker. Studia Linguistica, 68, 49-76.

Haegeman, L., \& Hill, V. (2013). The syntactization of discourse. Syntax and its limits, 370-390.

Hirschberg, J., \& Litman, D. (1993). Empirical studies on the disambiguation of cue phrases. Computational linguistics, 19, 501-530.

Ingham, B. (1994). Najdi Arabic: Central Arabian (Vol. 1). John Benjamins Publishing.

Ippolito, M. (2007). On the meaning of some focus-sensitive particles. Natural Language Semantics, 15, 1-34.

Reichenbach, H. (1980). Elements of symbolic logic.

Rizzi, L. (1997). The fine structure of the left periphery. In Elements of grammar, 281-337. Springer Netherlands.

Roussou, A. (2000). On the left periphery: Modal particles and complementisers. Journal of Greek Linguistics, 1, 65-94.

Schourup, L. (1999). Discourse markers. Lingua, 107, 227-265.

Stede M. and Schmitz B. 2000 Discourse particles and discourse functions. Machine translation, 15, 125-147.

Strauss, S., \& Xiang, X. (2009). Discourse particles: Where cognition and interaction intersect-The case of final particle ey in Shishan dialect (Hainan Island, PR China). Journal of Pragmatics, 41, 1287-1312.

Struckmeier, V. (2014). Ja doch wohl C? Modal Particles in German as C-related elements. Studia Linguistica, 68, $16-48$.

Taboada, M. (2006). Discourse markers as signals (or not) of rhetorical relations. Journal of Pragmatics, 38, 567-592.

Taha, K. T., Jarrah, M. A., \& Al-Jarrah, R. S. (2014). The Discoursal Arabic Coordinating Conjunction Wa (And). International Journal of Linguistics, 6, 172-183. http://dx.doi.org/10.5296/ijl.v6i4.4547

Zimmermann, M. 2004. Discourse particles in the left periphery. ZAS Papers in Linguistics, 35, 543-66.

Zimmermann, M. (2011). Discourse particles. Handbook of Semantics. Berlin: Mouton de Gruyter.

Zwicky, A. M. (1985). Clitics and particles. Language, 283-305.

\section{Notes}

Note 1. It should be made clear that the particles included in this section are not all particles used in NHA. There are some other particles not addressed here since they are being investigated. This research is meant to capitalize on the particles not receiving any attention.

Note 2. It should be noted that there are other uses of this particle in other Arabic varieties such as Jordanian Arabic, including its use as a negative polarity item (cf. Alsarayreh 2012 and Alqassas 2015).

Note 3. All the information in this section (i.e., data, dialogue and discussion etc.) are adopted (slightly modified) from Alshamari (2015b) for which I refer the reader for further details on the variety of uses for this particle.

Note 4. All the information in this section (i.e., data, dialogue and discussion etc.) are adopted (slightly modified) from Alshamari (2015b) for which I refer the reader for further a variety of uses for maar. 